\title{
The Role of the European Education Area in European Union Integration in Times of Crises
}

\author{
IR Y N A K USHNIR \\ Nottingham Trent University, Nottingham Institute of Education, Clifton Campus, \\ NG11 8NS, UK. Email: iryna.kushnir@ntu.ac.uk
}

The European Union has faced many crises, such as populism, xenophobia, economic and political challenges, to name a few. This has resulted in some questioning whether the EU will survive. Herein, the neo-institutionalist perspective on crises in EU integration frames an original and timely inquiry into the role of a new EU initiative - the European Education Area - in supporting EU integration in these challenging times. This inquiry relies on a thematic analysis of relevant key policy materials. The findings highlight that while it is not surprising that the EEA is an example of an education convergence project in the EU, the novelty of other findings is striking. It appears that the crises in the EU inspired the authors of the EEA to utilize its education as a tool for EU deepening, which is an aspect of EU integration related to the strengthening of the relationships amongst its Member States. Specifically, the EEA has been a driver in the development of a common European identity and European economy, the EU as a socially-just society and the continent of progress. These findings address important gaps of our knowledge about the role of education in driving EU integration.

\section{Introduction}

The European Union (EU) has faced many crises in its recent past, such as populism, xenophobia, economic and political challenges, to name a few (Falkner 2016; Taggart and Szczerbiak 2018). This has resulted in some questioning whether the EU will survive (Murray and Longo 2018). Crises, however, are not new in the EU, and actually, they are integral to a cyclical process of EU integration (Scipioni 2017). Based on EU integration literature, such as La Barbera (2015) 
and Kushnir et al. (2020), EU integration in this article is defined as a threefold process that comprises: (1) the structuring and strengthening of the relationships among the existing Member States (MSs) (which can take two forms: deepening or differentiated integration); (2) widening the EU to attract and include new MSs; and (3) shaping the relationships of the EU with the exiting state - the UK.

Herein, the neo-institutionalist perspective on crises in EU integration is used to frame an original and timely inquiry into the role of a new EU initiative - the European Education Area (EEA) - in supporting EU integration in these challenging times. The website of the European Commission (EC 2020) details that the EEA is an EU project, which commenced in 2017 to enable 'all young people to benefit from the best education and training, and to find employment across Europe'. The EEA comprises a number of initiatives across all levels and types of education in the EU, such as: mutual recognition of diplomas, quality in early childhood education and care, language learning, key competencies for lifelong learning, the digital education action plan, common values, the European universities initiative, and the European student card initiative. This inquiry relies on thematic analysis of EEA key policy materials. It has generated important findings about the EEA being an example of the integration of the education policy-field in the EU and, more importantly, a tool for EU integration. This article details these findings and demonstrates how they address important gaps of our knowledge about the role of education in driving EU integration.

\section{EU Integration in Times of Crises: Neo-institutionalist Perspective}

This section takes the neo-institutionalist lens and unpacks the meaning of EU integration in more detail, paying particular attention to its three aspects. This section also relies on neo-institutionalism to explain EU crises as the processes that shape EU integration.

Neo-institutionalism or new institutionalism may be viewed as an updated version of the institutionalist theory. Institutionalism that is focused more on a static position of organization: why organizations are resistant to reforms and how they resist reforms, how structures within organizations perpetuate themselves and why wider forces ensure the stability of organizational practices (Burch 2007). New institutionalism, on the other hand, emphasizes the processes of change, rather than stability in organizations.

Neo-institutionalism is a broad stream of thought that explains organizational behaviour by considering how institutions interact among one another and with society, and how institutions change under the influence of wider processes (Peters 2019). The analysis in this article appeals, first and foremost, to the last aspect of the definition of neo-institutionalism by focusing on the EU context of crises as an example of the wider processes that influence EU integration. According to Peters (2019), crises are factors that influence the way organizations behave. The discussion of the aspects of EU integration is also informed by neo-institutionalism, 
particularly its emphasis on how institutions interact among one another. Different configurations of the relationships amongst different groups of countries that illustrate each of the aspects of EU integration can be seen as the expression of the interaction of various EU's components, such as national governments and other national and regional organizations.

\subsection{EU Integration and its Aspects}

Most of pre-Brexit-vote studies conceptualized integration, on one hand, as structuring and strengthening the relationships among the existing MSs, and on the other hand, as widening the EU to attract and include new MSs - enlargement (e.g. Csergo and Goldgeier 2004; La Barbera 2015). Brexit was the milestone that triggered the emergence of the studies that considered a third aspect of EU integration - shaping relationships of the EU with the exiting state - the UK, such as in Kushnir et al. (2020).

Enlargement is usually discussed in terms of whether it has advantages for the EU (Grabbe 2014). There were a few waves of EU enlargement: in 1995 when Austria, Finland and Sweden joined; then in 2004 when the Czech Republic, Cyprus, Estonia, Hungary, Latvia, Lithuania, Malta, Poland, Slovakia and Slovenia joined; in 2007 when Bulgaria and Romania joined, and finally in 2013 when only Croatia joined (European Council 2017).

One of the greatest debates in the literature regarding the structuring and strengthening of the relationships among the existing MSs has been about how successfully new MSs integrate after accession. The two commonly discussed options of the development of the relationships amongst the MSs in the literature has been deepening and differentiated integration. Deepening is an ideal and the smoothest format of the relationships amongst the MSs with the same level of value-sharing and cooperation among all MSs in all policy areas (La Barbera 2015). To complement this definition, Ahrens et al. (2005) suggest that deepening is the opposite of fragmentation in the relationships among the MSs, and Chamon and Van der Loo (2014) express a concordant idea - that deepening is not heterogeneity. The latter scholars explain that deepening is related to the intensification of the cooperation among the MSs that act as members of a 'club'.

Differentiated integration is unavoidable in practice, according to Stubb (1996). Stubb argued, over 20 years ago, that:

The debate about differentiated integration ... is characterised by an excess of terminology which can give even the most experienced specialist of European integration a severe case of semantic indigestion. Two-speed, multi-speed, step-by-step, strengthened solidarity, graduated integration, hard core, variable integration, concentric circles, two-tier, multi-tier, multi-track, two-track, 'swing-wing', circles of solidarity, variable speed, imperial circles, pick-and-choose, overlapping circles, structural variability, opt-in, opt-out, opt-up, opt-down, bits-and-pieces, ad libitum integration, multilevel, two-level, restrained differentiation, flying geese, magnetic fields, hub-and-spoke and many circles, are a few examples of the rhetoric in English. (Stubb 1996, 283; emphasis in original) 
This terminological diversity can be traced in later studies too, such as Gotz (2006, 109) who discusses non-convergence tendencies in the EU and coins the term 'clustered Europeanization'. This notion could be illustrated by Fletcher's $(2009,71)$ account of the "balancing of the United Kingdom's "Ins" and "Outs" in the EU before Brexit happened. Now, however, the case of the UK illustrates the third aspect of EU integration - structuring relationships between the EU and an exiting state.

The negotiation of the relationships between the EU and the UK, including when and under what conditions the UK leaves the EU, has been a long and complicated process. The disagreements existed not only between the EU and the UK but also within the EU and the UK (Hobolt 2018). Following Brexit, other exits of MSs are seen as plausible by Oliver (2017).

\subsection{Crises in the $E U$}

A significant theme in the debates around EU integration from the neo-institutionalist perspective is the implications of the EU's crises for EU's existence. Falkner $(2016,220)$ presents the recent context of the EU as the 'conglomerate of specific but interconnected crises'. This author focused only on the relationship between the financial, economic and external relations crises. There is literature that highlights other crises and the connections between them. For example, Balkan (2016) mentions the link between the migrant crisis on one hand, and humanitarian and political crises in the EU on the other hand. Taggart and Szczerbiak (2018) discuss how the migrant crisis in the EU produced new problems, including rising Euroscepticism. Moreover, there is a tendency to slow down EU integration by the insiders of the EU institutions, who have been growing in number and promoting Eurosceptic ideas (Medrano 2012). Seabrooke and Tsingou (2018) also discuss the Global Financial Crisis, the Eurozone crisis, the security crisis and the migrant crisis. The most recent Coronavirus and health crisis that exposed healthcare weaknesses in the EU (Leonardi et al. 2020) has triggered the start of an economic meltdown in the region and beyond.

These problems have raised the question in the literature of whether the EU will survive (Murray and Longo 2018; Wolf and Ossewaarde 2018). However, crises are not a new phenomenon in the EU. They are integral to EU integration, which is a cyclical process (Scipioni 2017). While the crises in the past eventually drove further integration, the current crises seem to be threatening the existence of the EU (Seabrooke and Tsingou 2018), as MSs have been advocating the re-nationalization of policies (Brekke and Staver 2018) and considering differentiated integration (Gotz 2006). Postelnicescu $(2016,201)$ argues that.

Europe is nowadays at a crossroad, divided between the need to remain faithful to its core democratic values and freedoms, maintaining an area of freedom and justice and the need to protect its citizens against the new terrorism and the rise of nationalistic leaders and parties that require less Europe and more power back to the nation states. 
Post-war peace-building and ensuring security on the continent was the main pillar of EU integration that inspired the emergence of the EU and its development in the aftermath of the Maastricht Treaty (Dedman 2009). Adherence to this principle remained but it subsided with time, giving way to the search of new drivers of EU integration, as suggested by Polyakova (2016). The author states that

Mainstream politicians too often rely on the worn-out trope of a Europe "whole, free, and at peace'-a phrase that spoke to generations that remembered World War II and the Cold War. But younger Europeans are searching for a vision for the future that speaks to their values now, not to ideals that emerged out of past calamities. (Polyakova 2016, 70)

The author states this despite the fact that the EU did set up a new goal for itself at the Lisbon European Council meeting in 2000 - to become the most competitive knowledge-based economy in the world (European Parliament 2000). Perhaps the new goal did not compare with the old goal in the degree of its importance, and thus has not managed to fill the gap that the fading idea of the peace-building started to create.

Westlake (2002) suggests that EU integration by its nature is fluid, which suggests that a degree of fluidity is present in all three aspects of EU integration. Delors (2002: ix) agrees with the idea of the fluidity and explains it elaborately with a metaphor:

... the fundamental question which the contributors [to the book] confront is how the integration process can be kept on course in a situation of perpetual flux. The collective answer they give is that, like the navigation of a ship, we can only keep to a course by reference to a set of fixed values. The set includes a mix of normative and positive values, most found in the treaties themselves: peace, prosperity, nondiscrimination, pluralism, democracy, economic freedom, solidarity and social cohesion.

This section has explained how EU crises can be positioned as the processes that shape EU integration. It has also unpacked key aspects of EU integration, which form parts of its definition. It is important now to identify the debates about EU integration within the scholarship that focuses predominantly on education.

\section{Education and EU Integration}

There are two main bodies of literature that explore the relationship between education and EU integration. One of them is quite large; it focuses on the integration of the education policy filed in the EU. The other body of literature suggests a possible important role of education in guiding the development of EU integration. However, this body of literature is limited. It is important to note that there are a lot of studies that use the term 'integration' with a different meaning from how it is conceptualized in this article. Those studies focus on the integration of minority groups in education in the EU (e.g. Siemienski and Packer 1997). Such studies are beyond the scope of this article. 
The first body of literature mentioned above, often presents its focus as the integration of the education policy field in the EU (e.g. Field 2003; Kwiek 2007). A lot of studies that investigate specifically European higher education are mainly about the Bologna Process - a policy initiative to harmonize higher education structures and promote the European dimension of higher education. It started off as an EU initiative but it eventually expanded far beyond the borders of the EU (EHEA 2020). These studies focus on the following key aspects of the influence of EU integration on higher education: the change of governing of higher education on the national level and the change of governing of higher education institutions (Lowe 1992; De Wit 2003; Charlier and Croche 2005; Maasen and Olsen 2007; Maasen and Musselin 2009), the change of governing of research in higher education (Amaral et al. 2009), the impact of EU integration on private higher education institutions (Kwiek 2007), the European integration of higher education through student mobility (Papatsiba 2006), as well as the achievements and challenges in the implementation of Bologna in national contexts (e.g. Wetzinger 2019). There is research into integration tendencies in education in Europe in general, not limited to higher education, which was referred to as a 'European education area' (Lawn 2003; Grek and Lawn, 2009). However, those references meant a European education space in general, as they were not related to the EEA that was officially initiated by the EU in 2017. A number of other references to a 'European Education Area' can be found in the literature prior to 2017 (Kirkwood-Tucker 2004; Burnett 2007; Lentner 2007; Salimova et al. 2012; Fernández 2014). These references are used as the synonyms of 'the European Higher Education Area'. A formal start of work on the development of the EEA in 2017 as a separate initiative is likely to reserve the usage of the reference 'the European Education Area' for the 2017 initiative only.

The literature on the EEA, which is of interest in this article, is limited. The EEA is explored from the following angles in the scholarship: the digitalization of education in the EU (Salajan 2019; Decuypere and Simons 2020), student mobility within the EEA (Grinberga-Zalite et al. 2018), a national response to the initiative illustrated by the case of Croatia (Kasap et al. 2018), and the governance of the EEA which resembles the governance of the EU through the creation and expansion of the interest groups that coordinate stocktaking and benchmarking (Cone and Brøgger 2020). These standardization tendencies are often presented as examples of the integration of the EU policy field in the area of education, although they are not placed within a wider EU integration process and not discussed in relation to EU integration aspects, such as strengthening the relationships among its MSs, candidate countries and exiting countries.

The second and limited body of literature recognizes that education may play a role in guiding the development of EU integration. According to Grek $(2008,208)$, education started emerging as a key policy-making mechanism in the EU after its formal establishment: ' . . . education is slowly moving from the margins of European governance to the very centre of its policy making'. Corbett (2005), Robertson (2008) and Robertson et al. (2016) suggest that, specifically, higher education has played a role in crafting the EU project through the facilitation of 
academic mobility, aiding the creation of a European single market and a European citizen. Kushnir (2016) states that the Bologna Process, mentioned earlier, which became the largest higher education initiative in the world, was originally an EU initiative that was eventually transformed into a wider European project that crossed the borders of the EU to encompass geographical Europe and some countries beyond that as well. The author puts forward a provocative argument that the 48 countries, which have been implementing the Bologna Process with the focus on facilitating a European identity through higher education, witnessed building up tensions in the development of 'territory-identity compatibility in Europe' (Kushnir 2016). The author illustrates this by the following example,

Russia's membership in the EHEA is an interesting case. Its authoritarian government and anti-western ideology (Kuzio 2012) seems to be at odds with the European values, associated with the respect to diversity, mentioned above. Solutions to this discrepancy between one growing space and non-unified identity of its peoples have been sought for but never found. (Kushnir 2016, 672)

According to the author, the Bologna Process was one of the tools for achieving the goal that the EU set for itself at the Lisbon European Council meeting in 2000, which was mentioned earlier in this article - to become the most competitive knowledge-based economy in the world. It comes as no surprise then that Polyakova (2016) admitted that no explicit changes had taken place in the EU since its inception and the mission of a post-war peace-builder.

The study reported in this article addresses important gaps in each of the two bodies of literature and establishes a link between them. This study furthers the research into the EEA as an example of the integration of the education policy field in the EU. This study also relies on the studies about EU integration in times of crises, presented earlier in the article, to expand the limited body of literature that recognizes that education may play a role in guiding the development of EU integration. This is done by exploring the role of the EEA in EU integration.

\section{Methodology}

The gaps in the literature highlighted above prompted the following research question: what role do the EC and the Council of the EU assign to the EEA in driving EU integration, integration that has been challenged by recent crises? The answer to this question was sought through the search of relevant key international policy materials on the website of the EC and qualitative thematic analysis of these materials, while relying on the neo-institutionalist view of crises as triggers of change in institutional behaviour. The data collection and analysis was conducted between January and March 2020.

Seven key documents of different types, issued between 2017 and 2019, were collected as well as the initial press release of the EC to announce the work towards the EEA. The choice of this timeframe was dictated by the commencement of the work on the EEA by EU leaders at their meeting on 17 November 2017 in Gothenburg, 
Table 1. Key themes and sub-themes.

\begin{tabular}{ll}
\hline \hline Themes & Sub-themes \\
\hline The context of crises & $\begin{array}{l}\text { Crises in the EU in general } \\
\text { Crises specifically in education in the EU } \\
\text { Crises allow to recognize achievement in the EU in general } \\
\text { Crises allow to recognize achievements specifically in the } \\
\text { area of education in the EU } \\
\text { The EU has to overcome the crises } \\
\text { General characteristics } \\
\text { Deepening in specific aspects of the EEA } \\
\text { Education in the EEA as an integration tool } \\
\text { EU deepening through the } \\
\text { deepened EEA }\end{array}$ \\
\hline \hline
\end{tabular}

Sweden, and the fact that the latest relevant key documents at the time of the data collection were issued in 2019. The following documents were collected in addition to the press release of the EC by Bertaud et al. (2017): a resolution of the Council of the European Union (2019) and six documents by the EC, including two communications of the EC issued in 2017 and 2018, a report by Directorate-General (DG) for Communication (2018), three supplementary documents by the EC presented at the EEA section of the EC website (EC 2020) (see the Appendix). This selection of documents represents all the documents presented as key documents in the press release by Bertaud et al. (2017) and the EEA section of the EC website (EC 2020).

Manual thematic analysis of these materials was conducted. The thematic analysis followed Rubin and Rubin's (2012) guide for open and axial coding of themes. Open coding entailed breaking down the data in the documents into themes, subthemes, sub-sub-themes and so on, while being open to different insights. The open coding was guided by the theoretical ideas around EU integration in times of crises presented earlier in this article. Three main themes were identified: 'the context of crises', 'deepening of the EEA', and 'EU deepening through the deepened EEA'. A number of sub-themes were identified within each of these themes (see Table 1).

Each of the sub-themes was further sub-categorized to detail the types of crises, aspects, etc. They provided a list of relevant quotations from the EEA materials, which generated those themes, sub-themes and so on. The open coding of themes partially relied on the key concepts in their different linguistic forms that helped to generate some themes, such as the words 'crisis', 'challenge', 'difficulty', 'uncertainty', 'struggle', 'problem' and 'shortage' in the first theme, 'the context of crises', for instance. Additionally, the open coding for the themes relied on the overall meaning of sentences that could convey the same ideas without explicitly mentioning any of the crisis-related synonyms. For instance, the sentence 'Europe does not excel in delivering high-quality skills' (EC 2017, 2) does not contain any of the crisis-related terms, but it conveys a crisis-related meaning by using other linguistic tools, such as the negation of the desirable. The themes and their subordinate themes from the open 
coding were regrouped in the axial coding, consequently highlighting the nature of the relationship amongst them. The thematic analysis was recorded on 22 pages of a Word document.

\section{The EEA as a Tool for EU Deepening in the Context of EU's Interlocking Crises}

This section provides a discussion of the findings from the thematic analysis of the materials collected for this research. The findings demonstrate that the EU positions the EEA in these materials as an example of integration in the EU education policy field. More importantly, the EU positions the EEA as a tool for the EU to overcome the crises it has been dealing with by facilitating EU deepening, which is an aspect of EU integration.

\subsection{Crises-related Context of the EEA}

The data support Falkner's $(2016,220)$ statement about the 'conglomerate of specific but interconnected crises' in the EU's recent past and present. The documents about the EEA and the press release mention two groups of crises: specifically in the field of education and in general in the EU as an organization.

The EEA materials highlight the following crises in the area of education: obstacles to student mobility within the EU because of legal obstacles imposed by borders and financial constraints (Bertaud et al. 2017; EC 2017; DG for Communication 2018; EC 2018b), a number of gaps in student participation in education on different levels, particularly gender disparity in choosing to study science, technology, engineering and mathematics, the lack of pursuing inter-disciplinary studies and the lack of the participation of adults in lifelong learning (EC 2017), the shortage of digital equipment in schools and IT professional development programmes for teachers (EC 2017; EC 2019b), the existence of a large share of low achievers in education, most of whom come from households with low levels of income or education and do not progress upwards on the social ladder (EC 2017; EC 2018b). Some of these challenges resonate with what is also discussed in other studies about the EEA, such as the issues with mobility (Grinberga-Zalite et al. 2018) and digitalization (Salajan 2019).

The other group of crises that the EEA materials highlight is also discussed in the literature about EU integration (Balkan 2016; Falkner 2016; Taggart and Szczerbiak 2018; Seabrooke and Tsingou 2018; Reusken et al. 2020): economic, security and external relations crises (EC 2017), migration crisis (Bertaud et al. 2017; EC 2017; EC 2019b), political crisis (Bertaud et al. 2017; EC 2017; Council of the EU 2019) and health crisis (EC 2019b). Aside from these crises, a number of other overlapping crises in the EU feature in the EEA materials: populism (Bertaud et al. 2017; EC 2017; EC 2018a), the phenomenon of 'fake news' and the population's media illiteracy (Bertaud et al. 2017; EC 2017; EC 2019b; Council of the EU 2019; EC 
2018a), xenophobia (Bertaud et al. 2017; EC 2017; EC 2018a), discrimination (EC 2018a), the risk of radicalization (EC 2017), the crisis of democracy (EC 2017; EC 2019b), unemployment (EC 2017), a gap between a rising skills demand by employers and the skillset of the population (EC 2017; EC 2019b; Council of the EU 2019), persistent social inequalities (EC 2017; Council of the EU 2019), ageing population (EC 2017; Council of the EU 2019), the overall underperforming of the EU in its excellence in different areas in comparison to other countries, particularly Asian countries (EC 2017). Moreover, the materials that were analysed mention a couple of globalization challenges that the EU faces, such as climate change (EC 2019b; Council of the EU 2019) and sustainability problems (Council of the EU 2019).

As mentioned earlier, a few scholars expressed concerns about the future of the EU in the context of the ongoing crises (Murray and Longo 2018; Wolf and Ossewaarde 2018). The fact that EU integration has been questioned by the recent challenges could also be traced in most of the EEA materials in the statements that more unity in the EU should be promoted (Bertaud et al. 2017; EC 2017; DG for Communication 2018; EC 2019a). Furthermore, it is stated in the 2017 Communication that 'President Juncker set out his views for a more united, stronger and more democratic Union in his 2017 State of the Union Address' (EC 2017: 1). Such statements illustrate the neo-institutionalist approach of the EU to its integration as it has been adapting to deal with the crises. These crises are examples of the contextual processes that influence the course of EU integration.

However, the existence of the EU as an institution in the future is not questioned in these materials. Instead, the crises put things into perspective and allowed the EU to recognize its achievements in its integration as an institution in general, as well as in the area of education in particular. The EU as an institution is referred to as a 'unique project', which 'has changed our lives for the better' (EC 2017, 2, 12). One of the greatest achievements of the EU 'was to build bridges across our continent with the creation of an area of free movement for workers and citizens' (Bertaud et al. 2017). It has become a 'continent of excellence' which 'has the most equal and inclusive societies in the world with high life expectancy and strong social protection systems', which has been promoting 'cultural diversity for 30 years' (EC 2017, 9) and whose 'common values such as the rule of law and fundamental rights are safeguarded and promoted' (Council of the EU 2019, 5). What concerns education in the EU, an excellent track-record of promoting mobility is acknowledged (EC 2017; DG for Communication 2018). It is also mentioned that 'Education and training systems in Europe are in general of good quality' and that the EU is already 'an attractive place to study' (EC 2017, 4). Aside from prompting the EU to take stock of its achievements, the crises sparked an intensive debate about shaping a vision for the future of the EU: 'The debate about the future of Europe is in full swing' (EC 2017, 1), 'As we look to Europe's future' (Bertaud et al. 2017), 'setting a vision for 2025 and beyond' (EC 2019a, 2). Searching for a new vision to ensure further integration is in line with Scipioni's (2017) argument that crises inspire further integration in the EU. 
Part of this vision is deepening the EEA itself and another part of it is deepening the EU overall in result, as discussed below.

\subsection{The Deepening of the EEA}

The following quote is the most telling in terms of what the EC is invited to do:

... Fully exploit the potential of all relevant fields of education and training with a view to deepening the European Education Area. (Council of the EU 2019, 8)

The word 'deepening', which is used here in relation to the EEA, suggests the aim to deepen the relationships of the MSs in the area of education through the development of the EEA and converging education in it. The language, such as 'shared agenda', 'common goals', 'working together', dominates the discussion of the converging education trends in the EU. This language pertains to the deepening of the relationships amongst the MSs particularly because the EEA is solely an EU initiative (EC 2020).

The meaning of the deepened EEA, in a nutshell, can be represented by a quote from EC $(2017,11)$ :

A vision for 2025 would be a Europe in which learning, studying and doing research would not be hampered by borders. A continent where spending time in another MS - to study, to learn, or to work - has become the standard and where in addition to one's mother tongue speaking two other languages has become the norm.

The studies about the EEA imply deepening, but never discuss it explicitly. For instance, Salajan (2019) and Decuypere and Simons (2020) discuss the growing digitalization of education in the EEA and relevant standardization trends in education in the EU countries; Grinberga-Zalite et al. (2018) analyse the convergence of student mobility opportunities around the EU in the EEA. Additionally, Cone and Brøgger (2020) analyse the international mechanisms in the EU and Kasap et al. (2018) look at the national mechanisms that are used to promote the cooperation among the MSs in their development of the EEA.

\subsection{EU Integration Through the Deepened EEA}

The deepening of the EEA is related to supporting EU integration more widely in these challenging times. Specifically, education in the EEA is presented in the EEA materials as a tool for the structuring and strengthening of the relationships amongst its MSs, particularly their deepening.

\subsubsection{Education in the EEA as an Integration Tool}

As explained earlier in this article, there is a limited number of studies that suggest that education may play a role in EU integration (e.g. Grek 2008; Kushnir 2016). The analysis of the EEA materials supports the idea of education being at the centre 
of policy-making: 'The debate placed education and culture at the top of the policy agenda' (EC 2018a, 2). This analysis also provides much clearer references to the idea that education in the EEA is seen by the EC and the Council of the EU as a tool for EU integration. The title of the 2018 Communication of the EC is a telling example Building a Stronger Europe: The Role of Youth, Education and Culture Policies (EC 2018a). Moreover, EC (2018b, 1) explicitly discusses the idea of 'unlocking the potential of education and training to support the European project', similarly to how EC (2018a, 2) put it: 'More attention needs to be devoted to education, training and culture enabling them to unlock their full potential to support the European project'. This is also in line with the press release of the EC by Bertaud et al. (2017) that mentions using 'culture and learning as a driver for unity'.

As a reminder, the term 'EU integration' was defined earlier in the article, as a process including structuring and strengthening the relationships among the existing MSs, widening the EU to attract and include new MSs - enlargement, and shaping the relationships of the EU with the exiting state - the UK. The first aspect of it related to the relationships among the existing MSs - is what is stated in the description of the EEA on the website of the EC (2020) as well as being emphasized in the EEA materials. It was also mentioned earlier in the article that this aspect of EU integration can take two forms. One is deepening, which is the format of the relationships amongst the MSs in which the MSs are the members of the same 'club' and share the same values and contribute equally to the development of their common policy areas (Ahrens et al. 2005; Chamon and Van der Loo 2014; La Barbera 2015). The other form is differentiated integration, which is about the emergence of the clusters of countries which strive for more or less close relationships in different policy areas (Stubb 1996; Gotz 2006; Fletcher 2009).

While the EEA materials do not explicitly state which type of relationships amongst the current MSs the EEA is meant to promote, it could be inferred that they focus on deepening. This idea can be traced in the following exemplary quotations from these materials about shared cultural heritage, common European identity and unity, while recognizing and cherishing diversity: 'The need to foster a greater sense of belonging in face of populism and xenophobia' (Bertaud et al. 2017), 'a more united, stronger and more democratic Union' which would 'benefit from the rich European cultural heritage' (EC 2017, 1), 'a continent in which people have a strong sense of their identity as Europeans' (EC 2017, 11), 'a Union which preserves our cultural heritage and promotes cultural diversity' (DG for Communication 2018, 2), and 'bring[s] Europeans together' (EC 2019a, 2). The recurrent reference in the EEA materials to the EU as 'a continent' may imply a reduced significance of the borders among the EU countries as a type of obstacle in the deepening of the relationships of the MSs. This can be supplemented by other references that convey a similar meaning, such as: 'The European project has always been about overcoming borders and allowing for free movement' (EC 2017, 4), it presupposes working 'seamlessly across borders' (Bertaud et al. 2017; EC 2017, 4), seeking convergence (EC 2017; Council of the EU 2019), and promoting 'cross-border' initiatives and cooperation (DG for Communication 2018, 2; Council of the EU 2019, 
10). The references are in line with La Barbera's (2015) view of EU deepening. Despite the EU being presented in the EEA materials as a continent with a reduced significance of its internal borders, the rule of subsidiarity of the EU initiatives to MSs' national-level policymaking in general is acknowledged. This could be illustrated by the following quote: ' ... set out possible ways forward in line with the principle of subsidiarity... The Union's competences are limited to encouraging cooperation, supporting and complementing national action' (EC 2017, 2). Even in these quotations, references to differentiated integration of the EU MSs are absent.

\subsubsection{The Aspects of EU Deepening that are Promoted Through the EEA}

The literature about EU deepening that was cited above explains the overall idea of deepening. However, it fails to detail a range of aspects of this format of the strengthening of the relationships amongst the MSs. My analysis below relies on the definition of deepening and generates a list of its aspects, which are promoted by the EEA: common European identity, integrated economy, socially just society, a continent of progress. The generation of these aspects is in line with Westlake's (2002) argument that EU integration by its nature is fluid, which suggests that its aspects can be shaped.

Common Identity. The EEA materials present a common European identity as both already existing, which needs to be strengthened through education, and as something that needs to be developed through education in the EEA:

... strengthening our European identity remains essential and education and culture are the best vectors to ensure this. (EC 2017, 2, emphasis added)

It is education that helps us adapt to a rapidly changing world, to develop a European identity. (Bertaud et al. 2017, emphasis added)

The role of education for the common European identity is discussed extensively in most of the EEA materials, as illustrated in the quotes above. There are also other terms used synonymously with the concept of 'identity', such as 'the sense of belonging together', 'being part of a cultural community', 'common values', common 'citizenship':

... the future role of education and culture in strengthening the sense of belonging together and being part of a cultural community... education and culture as drivers for jobs, social fairness, active citizenship as well as means to experience European identity in all its diversity ... Education, culture and sport have a pivotal role in promoting active citizenship and common values amongst the youngest generations. (EC 2017, 2-3, emphasis added)

The role of education and training in promoting citizenship and democracy, personal development, social inclusion, equal opportunities and empowerment, and in fostering wellbeing and supporting cohesive societies. (Council of the EU 2019, 2, emphasis added) 
The idea of the common European identity is presented in the EEA materials in a tight interrelationship with the recognition of diversity and the international nature of the EU:

It is in the shared interest of all MSs to harness the full potential of education and culture as drivers for job creation, economic growth and social fairness as well as a means to experience European identity in all its diversity. (Bertaud et al. 2017, emphasis added)

Teachers play the central role... in fostering international perspectives early in a young person's life. (EC 2017, 7)

All of this is in line with Derrida's (1992) work, which highlights that the European identity-seeking process is a permanent process in the EU, and it is about building commonality together with the unavoidable respect for differences. Fostering the common identity in the EU is an aspect of EU deepening, which is promoted through education in the EEA. It is about homogenizing EU people's sense of belonging.

European Economy. Another aspect of EU deepening, promoted through education in the EEA, is the European economy with 'a truly integrated European labour market' (EC 2017, 4). It was explained earlier that the integration of the MSs may take one of two directions: deepening or differentiated integration. The phrase 'truly integrated labour market' is interpreted here as a deepened market, rather than a differentially integrated one. No references to heterogeneity in this integration are mentioned or implied in the EEA materials, but instead, terms such as 'convergence' in the economy are used (e.g. Council of the EU 2019, 5). The goal of deepening the European economy is also explicitly mentioned in the literature. For instance, Jancic $(2017,141)$ discusses 'a deepening Economic and Monetary Union'. The deepening of the European economy is meant to be driven by education, as suggested by the EC press release by Bertaud et al. $(2017,1)$ :

It is in the shared interest of all MSs to harness the full potential of education and culture as drivers for job creation, economic growth.

The EEA promotes increasing deepening of the European economy by considering its 'rapidly evolving labour market' in which skills needs are constantly changing (EC 2018a, 2). The EEA responds to this and supports the deepening of the European economy by helping to create 'a Union where young people receive the best education and training and can study and find jobs across the continent' (DG for Communication 2018, 2), and where work mobility across the continent 'has become the standard' (EC 2017, 11). The EEA can provide the education, which is a source of a resilient economy in the EU:

Education forms the basis for a creative and productive workforce ... education and training equip people with the skills they need on the labour market ... education, training, re- and up-skilling help to smoothen the transition between jobs; education 
and training give people the chance to create jobs themselves; a highly-qualified and flexible workforce forms the backbone of a resilient economy. (EC 2017, 3)

The 2017 and 2018 Communications (EC 2017, 11; EC 2018a, 2) call the EU's economy to-date as a 'social market economy', which combines 'economic freedom with social principles', and in which the knowledge of the society supports the development of its economy and 'socio-economic convergence' (Council of the EU 2019, 5). The knowledge of the EU's society remains a key driving factor in the EU's economic growth as the EU will be relying on education in the EEA to develop a more sustainable economy in the future:

It [education] will also be vital to steer the development and deployment of new technologies and support the Union's transition into a circular and low-carbon economy ... The potential of education and training to contribute to achieving a climate-neutral and green Europe needs to be fully explored. (Council of the EU 2019, 3)

Socially-just Society. In addition to a common European identity and integrated economy, the EU as a socially just society is another aspect of the EU's deepening supported with the help of education in the EEA.

The role of education and training in promoting citizenship and democracy, personal development, social inclusion, equal opportunities and empowerment, and in fostering wellbeing and supporting cohesive societies. (Council of the EU 2019, 2)

These ideas are also referred to as 'social fairness' in other EEA materials, such as in the EC press release by Bertaud et al. (2017, 1), the 2017 Communication (EC 2017, 2) and the 2018 Communication (EC 2018a, 10). The EEA materials explain that social fairness is being created in education and this will bear fruit in EU society overall. In particular, various inclusive education initiatives to support young people in the framework of the EEA 'will help give young people of all backgrounds more promising prospects and enable them to take a more active role in the European project' (EC 2018a, 7). The 2018 Communication is not the only document that discusses these initiatives from this perspective. Examples of similar initiatives in other documents include ensuring quality in early childhood education (DG for Communication 2018), learning two foreign languages in general education (EC 2017), making study and work mobility a reality (Council of the EU 2019). The discussions of all of these initiatives include the phrases 'for all', 'from all backgrounds' and 'removing barriers'.

$A$ Continent of Progress. The EEA materials provide references to the aims of the EC and the Council of the EU to use education as a tool to create the EU that would become a land of progress in all of its areas with opportunities for everyone, as well as excellence and competitiveness as its general characteristic. The EU is being built as a continent 'where citizens have new opportunities and social development and economic growth' and which would become 'a continent of excellence' (EC 2017, 5), 'international competitiveness' (EC 2019a, 2; 2018a, 2), 'allowing talent in Europe to flourish' (Council of the EU 2019, 3). 
Such an ongoing progress is planned to be supported through the development of the EU's resilience with the help of education in the EEA.

Investing in skills, competences and knowledge is essential to boost Europe's resilience. Such investments in people drive innovation, productivity and competitiveness. (EC 2018a, 2)

Boosting EU's resilience is essential, particularly now, in these challenging times:

Education is part of the solution to ... strengthen Europe's resilience in a context of the rapid and profound change induced by the technological revolution and globalization. (EC 2017, 2)

The analysis above has demonstrated that education in the deepening EEA is used by the EC and the Council of the EU in the EEA materials as a tool for EU deepening in the context of the broader challenges the EU has been experiencing with raising populism, xenophobia and other crises. In neo-institutionalist terms, these crises are the contextual powers that have prompted the EU to appeal to education as a tool for EU integration. This was done by creating the EEA and treating it explicitly as a tool for EU integration. These findings address a number of gaps, the most important of which is education acting as a driver of EU integration, represented by a growing, albeit limited, body of scholarship.

\section{Conclusion}

The EU project has been challenged by multiple crises significantly in its recent past. The research reported in this article was guided by the neo-institutionalist view of crises as influencing factors on the EU integration trajectory. The article set out to explain the role that the EC and the Council of the EU assign to the EEA in the EEA materials in driving EU integration that has been challenged by these crises. A thematic analysis of relevant key policy materials has revealed the following. While it is not surprising that the EEA is an example of an education convergence project in the EU, the novelty of other findings is striking. It appears that the recent crises have prompted the EU policymaking bodies that have been developing the EEA to utilize its education as a tool for EU deepening, which is an aspect of EU integration related to the strengthening of the relationships amongst its MSs. Specifically, the EEA, inspired by the crises, has been a driver for a common European identity, the European economy, the EU as a socially-just society and the EU as a continent of progress.

These findings make a significant contribution to three bodies of literature: the literature on the integration the education policy field in the EU, the limited literature on the role of education in driving EU integration and the EU integration literature. The findings bridge these bodies of literature in a novel way, by highlighting important links amongst them, and present an original insight into the role of the EEA in EU integration. 


\section{References}

Ahrens J, Hoen HW and Ohr R (2005) Deepening integration in an enlarged EU: a club-theoretical perspective. Journal of European Integration 27(4), 417-439.

Amaral A, Neave G, Musselin C and Maassen P (eds) (2009) European Integration and the Governance of Higher Education and Research. The Netherlands: Springer Netherlands.

Balkan O (2016) Disorder at the border: Europe's 'migrant crisis' in comparative perspective. Studies in Ethnicity and Nationalism 16(1), 116-120.

Bertaud N, Vandystadt N and Waldstein J (2017) Future of Europe: towards a European Education Area by 2025. Press Release of the EC, 14 November 2017. Available at https://ec.europa.eu/commission/presscorner/detail/en/IP_17_ 4521 (accessed 19 March 2020).

Brekke JP and Staver A (2018) The renationalisation of migration policies in times of crisis: the case of Norway. Journal of Ethnic and Migration Studies 44(13), 2163-2181.

Burch P (2007) Educational policy and practice from the perspective of institutional theory: crafting a wider lens. Educational Researcher 36(2), 84-95.

Burnett J (2007) Tilling the soil of the European higher education area. Educational Action Research 15(2), 283-293.

Chamon M and Van der Loo G (2014) The temporal paradox of regions in the EU seeking independence: contraction and fragmentation versus widening and deepening? European Law Journal 20(5), 613-629.

Charlier JE and Croché S (2005) How European integration is eroding national control over education planning and policy. European Education 37(4), 7-21.

Cone L and Brogger K (2020) Soft privatisation: mapping an emerging field of European education governance. Globalisation, Societies and Education, $1-17$.

Corbett A (2005) Universities and the Europe of Knowledge - Ideas, Institutions and Policy Entrepreneurship in European Union Higher Education Policy, 1955-2005. Basingstoke, UK and New York, USA: Palgrave Macmillan.

Council of the EU (2019) Resolution on further developing the European Education Area to support future-oriented education and training systems. Adopted 11 November 2019. Available at https://op.europa.eu/en/publication-detail/-/publication/ 9f1d16d1-09d1-11ea-8c1f-01aa75ed71a1/language-en/format-HTML/source113947200 (accessed 19 March 2020).

Csergo Z and Goldgeier JM (2004) Nationalist strategies and European integration. Perspectives on Politics 2(1), 21-37.

De Wit K (2003) The consequences of European integration for higher education. Higher Education Policy 16(2), 161-178.

Decuypere $M$ and Simons M (2020) Pasts and futures that keep the possible alive: reflections on time, space, education and governing. Educational Philosophy and Theory 1-13.

Dedman M (2009) The Origins \& Development of the European Union 1945-2008: A History of European Integration. New York: Routledge.

Delors J (2002) Foreword. In Westlake M (eds), The EU Beyond Amsterdam: Concepts of European Integration. New York: Routledge.

Derrida J (1992) The Other Heading: Reflections on Today's Europe. Bloomington, IN: Indiana University Press.

DG for Communication (2018) Flash Eurobarometer 466 Report: The European Education Area. EC, June 2018. Available at https://data.europa.eu/euodp/en/ data/dataset/S2186_466_ENG (accessed 19 March 2020). 
EC (2017) Communication from the Commission to the European Parliament, the Council, the European Economic and Social Committee and the Committee of the Regions - Strengthening European identity through education and culture: the EC's contribution to the Leaders' meeting in Gothenburg, 17 November 2017. Available at https://ec.europa.eu/commission/sites/betapolitical/files/communication-strengthening-european-identity-education-culture_en. pdf (accessed 19 March 2020).

EC (2018a) Communication from the Commission to the European Parliament, the European Council, the Council, the European Economic and Social Committee and the Committee of the Regions - Building a stronger Europe: the role of youth, education and culture policies. 22 May 2018. Available at https://ec.europa.eu/ transparency/regdoc/rep/1/2018/EN/COM-2018-268-F1-EN-MAIN-PART-1.PDF (accessed 19 March 2020).

EC (2018b) Unlocking the potential of education and training to support the European project. May 2018. Available at https://ec.europa.eu/education/sites/ education/files/factsheet-education-may2018-en.pdf (accessed 19 March 2020).

EC (2019a) European universities: Why? Available at https://ec.europa.eu/ education/sites/education/files/document-library-docs/european-universities-infosession.pdf (accessed 19 March 2020).

EC (2019b) European universities: a key pillar of the European Education Area. Available at https://ec.europa.eu/education/sites/education/files/document-librarydocs/european-universities-initiative-factsheet.pdf (accessed 19 March 2020).

EC (2020) Education in the EU: European Education Area. Available at https://ec. europa.eu/education/education-in-the-eu/european-education-area_en (accessed 19 March 2020).

EHEA (2020) Available at http://www.ehea.info (accessed 4 April 2020).

European Council (2017) EU enlargement. Available at http://www.consilium. europa.eu/en/policies/enlargement/ (accessed February 1, 2020).

European Parliament (2000) Presidency conclusions from the Lisbon European Council in 2000. Available at http://www.europarl.europa.eu/summits/lis1_en. htm (accessed 2 February 2020).

Falkner G (2016) The EU's current crisis and its policy effects: research design and comparative findings. Journal of European Integration 38(3), 219-235.

Fernández AD (2014) The future of European education: a political strategy \& four action areas. European Journal of Futures Research 2(1), 49.

Field H (2003) Integrating tertiary education in Europe. The Annals of the American Academy of Political and Social Science 585(1), 182-195.

Fletcher M (2009) Schengen, the European Court of Justice and Flexibility under the Lisbon Treaty: balancing the United Kingdom's 'ins' and 'outs'. European Constitutional Law Review 5(1), 71-98.

Gotz K (2006) Territory, temporality and clustered Europeanization. IHS Political Science Series working paper 109. Available at http://irihs.ihs.ac.at/1703/1/pw_ 109.pdf (accessed 1 April 2020).

Grabbe H (2014) Six lessons of enlargement ten years on: the EU's transformative power in retrospect and prospect. Journal of Common Market Studies 52(S1), $40-56$.

Grek S (2008) From symbols to numbers: the shifting technologies of education governance in Europe. European Educational Research Journal 7(2), 208-218.

Grek S and Lawn M (2009) A short history of Europeanizing education: the new political work of calculating the future. European Education 41(1), 32-54. 
Grinberga-Zalite G, Hernik J, Liepa E and Papins A (2018) Evaluation of Latvian students' learning experience in the European education area. Sociology 1(10). DOI: 10.17770/Iner2018vol1.10.3598

Hobolt S (2018) Brexit and the 2017 UK General Election. Journal of Common Market Studies 56(S1), 1-12.

Jancic D (2017) National Parliaments after the Lisbon Treaty and the Euro Crisis: Resilience or Resignation. Oxford: Oxford University Press.

Kasap J, Lachner V and Žiha N (2018) Through legal education towards a European Education Area. EU and Comparative Law Issues and Challenges Series (ECLIC) 2, 252-274.

Kirkwood-Tucker TF (2004) Toward a European model of higher Education: processes, problems, and promises. European Education 36(3), 51-69.

Kushnir I (2016) The role of the Bologna Process in defining Europe. European Educational Research Journal 15(6), 664-675.

Kushnir I, Kilkey M and Strumia F (2020) EU integration in the post 'migrant crisis' context: learning new integration modes? European Review 28(2), 306-324.

Kuzio T (2012) Twenty years as an independent state: Ukraine's ten logical inconsistencies. Communist and Post-Communist Studies 45(3-4), 429-438.

Kwiek M (2007) The European integration of higher education and the role of private higher education. In Private Higher Education in Post-Communist Europe. New York: Palgrave Macmillan.

La Barbera F (2015) Framing the EU as common project vs. common heritage: effects on attitudes towards the EU deepening and widening. The Journal of Social Psychology 155(6), 617-635.

Lawn M (2003) The 'usefulness' of learning: the struggle over governance, meaning and the European education space. Discourse: Studies in the Cultural Politics of Education 24(3), 325-336.

Lawn M and Grek S (2012) Europeanizing Education: Governing a New Policy Space. Oxford: Symposium Books Ltd.

Lentner C (2007) The competitiveness of Hungarian university-based knowledge centres in European economic and higher education area. Transformations in Business and Economics 6(2), 87-99.

Leonardi D, Polidori C and Polidori P (2020) The healthcare and pharmaceutical vulnerability emerging from the new Coronavirus outbreak. European Journal of Hospital Pharmacy. DOI: 10.1136/ejhpharm-2020-002278

Lowe J (1992) Education and European integration. International Review of Education 38(6), 579-590.

Maassen P and Musselin C (2009) European integration and the Europeanisation of higher education. In European Integration and the Governance of Higher Education and Research. Dordrecht: Springer.

Maassen P and Olsen JP (eds) (2007) University Dynamics and European Integration. Dordrecht: Springer.

Medrano JD (2012) The limits of European integration. Journal of European Integration 34(2), 191-204.

Mitchell K (2006) Neoliberal governmentality in the European Union: education, training, and technologies of citizenship. Environment and Planning D: Society and Space 24(3), 389-407.

Murray P and Longo M (2018) Europe's wicked legitimacy crisis: the case of refugees. Journal of European Integration, DOI: 10.1080/07036337.2018.1436543 
Oliver T (2017) The EU falling apart? Theoretical discussions of Brexit, Grexit and other exit scenarios. In Grimmel A and Giang S. (eds) Solidarity in the European Union. Cham: Springer.

Papatsiba V (2006) Making higher education more European through student mobility? Revisiting EU initiatives in the context of the Bologna Process. Comparative Education 42(1), 93-111.

Peters BG (2019) Institutional Theory in Political Science: The New Institutionalism. Cheltenham, UK: Edward Elgar Publishing.

Polyakova A (2016) The great European unraveling? World Policy Journal 33(4), 68-72.

Postelnicescu C (2016) Europe's new identity: the refugee crisis and the rise of nationalism. Europe's Journal of Psychology 12(2), 203-209.

Reusken CB, Broberg EK, Haagmans B, Meijer A, Corman VM, Papa A, Charrel R, Drosten C, Koopmans M and Leitmeyer K (2020) Laboratory readiness and response for novel coronavirus $(2019-\mathrm{nCoV})$ in expert laboratories in $30 \mathrm{EU} /$ EEA countries, January 2020. Eurosurveillance 25(6).

Robertson S (2008) 'Europe/Asia' regionalism, higher education and the production of world order. Policy Futures in Education 6(6), 718-729.

Robertson SL, de Azevedo MLN and Dale R (2016) Higher education, the EU and the cultural political economy of regionalism. In Global Regionalisms and Higher Education. Cheltenham, UK: Edward Elgar Publishing.

Rubin HJ and Rubin I (2012) Qualitative Interviewing: The Art of Hearing Data, 3rd edn. Thousand Oaks, CA: SAGE.

Salajan FD (2019) Building a policy space via mainstreaming ICT in European education: the European Digital Education Area (re) visited. European Journal of Education 54(4), 591-604.

Salimova T, Makolov V, and Enaleeva Y (2012) Quality management of higher education in the context of integration to European Education Area. European Journal of Business and Economics 5.

Scipioni M (2017) Failing forward in EU migration policy? EU integration after the 2015 asylum and migration crisis. Journal of European Public Policy, DOI: 10. 1080/13501763.2017.1325920

Seabrooke L and Tsingou E (2018) Europe's fast- and slow- burning crises. Journal of European Public Policy, DOI: 10.1080/13501763.2018.1446456

Siemienski G and Packer J (1997) Integration through education: the origin and development of The Hague recommendations. International Journal on Minority and Group Rights 4, 187-198.

Stubb A (1996) A categorization of differentiated integration. Journal of Common Market Studies 34(2), 283-295.

Taggart P and Szczerbiak A (2018) Putting Brexit into perspective: the effect of the Eurozone and migration crises and Brexit on Euroscepticism in European states. Journal of European Public Policy 25(8), 1194-1214.

Westlake M (ed.) (2002) The EU Beyond Amsterdam: Concepts of European Integration. New York: Routledge.

Wetzinger J (2019) Higher education reform in Moldova: achievements and challenges. International Higher Education (98), 28-30.

Wolf M and Ossewaarde M (2018) The political vision of Europe during the 'refugee crisis': missing common ground for integration. Journal of European Integration 40(1), 33-50. 


\section{About the Author}

Iryna Kushnir is currently a Senior Lecturer in Education Studies at Nottingham Trent University. She previously worked at the University of Sheffield and University of Edinburgh. Dr Kushnir's interdisciplinary research combines the following main areas: higher education, education policy, post-Soviet Europeanisation and migration. Her interdisciplinary approach has led to empirical and theoretical contributions which reveal how education policy on one hand and Europeanization processes and post-Soviet transition on the other hand are interrelated and mutually shape one another. 